\title{
Globe
}

Revue internationale d'études québécoises

\section{Andrée Lévesque : Scènes de la vie en rouge. L'époque de \\ Jeanne Corbin, 1906-1944, Montréal, Les Éditions du remue-ménage, 1999, 309 p.}

\section{Robert C.H. Sweeny}

Volume 3, numéro 2, 2000

URI : https://id.erudit.org/iderudit/1000592ar

DOI : https://doi.org/10.7202/1000592ar

Aller au sommaire du numéro

Éditeur(s)

Globe, Revue internationale d'études québécoises

ISSN

1481-5869 (imprimé)

1923-8231 (numérique)

Découvrir la revue

Citer ce compte rendu

Sweeny, R. C. (2000). Compte rendu de [Andrée Lévesque : Scènes de la vie en rouge. L'époque de Jeanne Corbin, 1906-1944, Montréal, Les Éditions du remue-ménage, 1999, 309 p.] Globe, 3(2), 198-200.

https://doi.org/10.7202/1000592ar d'utilisation que vous pouvez consulter en ligne.

https://apropos.erudit.org/fr/usagers/politique-dutilisation/ 
linguistes à l'esprit ouvert fassent contrepoids à la résistance têtue et quelque peu empreinte de mauvaise foi - de membres de l'Académie française. Le guide est utile et contribuera sans nul doute à renforcer la sécurité linguistique des francophones en matière de féminisation. On peut simplement regretter le peu de reconnaissance que ses responsables accordent aux qualités innovatrices des travaux du Québec en la matière...

\section{Noëlle Guilloton en coll. avec Pierrette Vachon-L'Heureux Office de la langue française}

\section{Andrée Lévesque}

Scènes de la vie en rouge

L'époque de Jeanne Corbin, 1906-1944

Montréal, Les Éditions du remue-ménage, 1999, 309 p.

L'idée est géniale : raconter aux jeunes militantes féministes d'aujourd'hui la vie d'une jeune communiste canadienne d'entre les deux guerres. Celle de Jeanne Corbin, une francophone issue des classes populaires, est un choix logique. Néanmoins, le défi est de taille, car il n'existe à son sujet que de rares sources documentaires. Née en France et élevée dans une ferme en Alberta, Jeanne Corbin fut une jeune militante communiste à Edmonton, à Toronto et à Montréal, avant d'œuvrer pendant dix ans à Timmins, une ville minière du nord de l'Ontario. Suivie de près par la Gendarmie royale depuis son adolescence, Corbin fut arrêtée à Toronto, harcelée à Montréal et incarcérée en Abitibi. Son bref séjour en prison, pour avoir suscité une émeute chez des bûcherons, porte atteinte à sa santé. À l'automne 1942, elle entre au sanatorium de London, en Ontario. Dix-huit mois plus tard, cette " héroïne du parti ", toujours confiante de la victoire prochaine du peuple, meurt. Elle n'avait que 38 ans.

Cette militante de la base fut toujours parrainée, sinon protégée, par des membres influents du parti. $\grave{A} 16$ ans, elle fait la connaissance 
d'un membre du comité central, Becky Buhay, et, cinq ans plus tard, à l'été 1927, elle devient son adjointe à l'école du parti. Instruite et bilingue, elle est envoyée en 1930 à Montréal où, sous la direction politique de Tom Ewen, le compagnon de Buhay et le chef de la Ligue d'unité ouvrière, elle s'occupe de la Ligue de défense ouvrière et de la rédaction de L'Ouvrier canadien. Enfin, à la Coopérative du Nouvel-Ontario, à Timmins, elle travaille sous la direction de Ronald Buck, le fils du chef du parti. Sans doute ce parrainage facilita-t-il quelque peu la tâche d'Andrée Lévesque, en ce sens où Corbin laissa, de par ses contacts divers, davantage de traces dans les archives. Mais il ne s'agit guère que de traces. De plus, ces fonds d'archives (ceux du parti et de la G.R.C.) ne nous offrent que deux aperçus partiels de la vie de Corbin, bien éloignés dans les deux cas des préoccupations quotidiennes d'une jeune militante. Certes, l'auteure fait de son mieux pour nous fournir le contexte. Néanmoins, ces rapports d'extériorité deviennent caractéristiques : les portraits d'époque priment ainsi sur les scènes de la vie, contrairement à ce que laisse entendre le titre. L'auteure aurait-elle pu faire autrement? Cela est rien moins qu'évident. Cependant, il me semble qu'au lieu de se limiter aux références directes à Corbin, Andrée Lévesque aurait pu la situer avec davantage de précision dans le corpus des rapports policiers. Une analyse comparative des sources, en effet, éclairerait mieux le lecteur. Après tout, combien de jeunes femmes canadiennes faisaient l'objet d'une filature constante de la part d'un surintendant de la G.R.C., voire du Commissaire lui-même? Bref, à défaut de sources personnelles, il importe de personnaliser les sources institutionnelles.

Bien qu'elle reproduise généralement de manière chronologique les étapes de la vie de Corbin, cette biographie s'en écarte au moins une fois, et cette exception est importante. Entre l'histoire des années passées à Timmins et le récit des mois de sanatorium se trouve un chapitre portant sur les "femmes dans un parti d'hommes ». À partir de recherches nouvelles et d'une synthèse critique de l'historiographie canadienne-anglaise, ce chapitre offre un bilan de la " question des femmes» chez les communistes entre les deux guerres. Probablement, pour de jeunes militantes et lectrices, il s'agira là de la partie la plus intéressante du livre. Pour moi, ancien militant et vieux 
lecteur, c'est le chapitre portant sur sa dernière lutte, au sanatorium, qui m'a touché le plus. Fort des lettres que Jeanne Corbin a écrites, ce chapitre $m^{\prime}$ a fait connaître une femme animée par une volonté claire de transformer ce monde. Voilà le véritable défi à relever, que Jeanne Corbin nous a laissé.

Robert C.H. Sweeny

Université Memorial of Newfoundland (Canada)

\section{Louise Desmarais}

Mémoires d'une bataille inachevée.

La lutte pour l'avortement au Québec, 1970-1992

Montréal, Trait d'Union, coll. « Histoire - Art. 35 », 1999, 441p.

Pour lancer sa nouvelle collection " Histoire - Art. 35 ", ainsi nommée pour dénoncer l'article du Code civil du Québec contraignant la pratique historienne en vue de protéger la vie privée des individus, les éditions Trait d'Union publient un ouvrage sur un sujet controversé écrit dans une perspective militante. Engagée dans la lutte pour le droit à l'avortement libre et gratuit au Québec, l'auteure est agente de recherche professionnelle. Son travail sur l'histoire de l'avortement au Québec comporte trois niveaux de lecture : le documentaire, le témoignage et le manifeste. Sur le plan documentaire, Louise Desmarais dresse une chronologie détaillée des faits relatant l'histoire de l'avortement au Québec. Ces éphémérides, couvrant plus de 300 pages, constituent la base de l'ouvrage et sont regroupées selon cinq périodes historiques. Si la première s'étend sur cent ans (1869-1969), les quatre autres concernent les deux décennies de la lutte proprement dite (1970-1992), soit la période que Louise Desmarais a vécue de près. Par son ampleur, cette partie de l'ouvrage est fort imposante; de plus, une excellente bibliographie, une filmographie et un index la complètent. $\mathrm{Et}$, de manière générale, l'ensemble montre fort bien les enjeux politiques et sociaux propres à la question de l'avortement, et révèle les points de vue des différents acteurs. Dans un deuxième temps, qui s'apparente cette fois au 